\title{
Testing the Deathdip and Deathrise Hypothesis: Ohio Mortality Results, 1989-1991
}

\author{
Ira Wasserman \\ Eastern Michigan University \\ Ypsilanti, Michigan, U.S.A. \\ and \\ Steven Stack \\ Wayne State University
}

\begin{abstract}
In a number of social science studies Phillips hypothesizes that individuals can control the timing of their deaths prior to such ceremonial events as birthdays, religious holidays and secular holidays. He also asserts that individuals who are more integrated into the social order, such as married people, are more likely to engage in this type of behavior. This study reanalyzes the hypothesis for birthdays. The study develops a multivariate model that controls for age, gender, marital status, and education. In order to determine whether there is a death-dip before birthdays, and/or a death-rise after birthdays, the research uses dummy variables that determine whether an individual is more likely to die a week before their birthday, and/or a week after their birthday. Using Ohio mortality data from 1989 to 1991 for individuals 18 years of age and older who died of natural causes, the study estimates the coefficients in the multivariate model. Age and seasonal effects, as well as interactions between age and gender and seasonal effects, are significant explanators of the difference between deathday and birthday. However, the study also found that individuals were more likely to die in the week after the birthday. The results lend support to the deathrise hypothesis.
\end{abstract}

\section{Résumé}

Dans un certain nombre d'études de sciences sociales, Phillips soutient que les gens peuvent contrôler le moment de leur mort en fonction d'événements marquants tels que leur anniversaire, une fête religieuse ou séculaire. Il propose également que les personnes les plus intégrées dans l'ordre social, les gens mariés par exemple, sont plus prédisposées à ce genre de comportement. La présente étude analyse de nouveau lhypothèse relative aux anniversaires et élabore un modèle multivarié qui contrôle l'âge, le genre, l'état matrimonial et l'éducation. Pour déterminer s'il y a une diminution des décès avant les anniversaires et/ou une recrudescence après les anniversaires, la recherche a recours à des variables fictives permettant d'établir si on peut prédire que la mort d'une personne surviendra plus probablement une semaine avant ou après son anniversaire. En utilisant les données de mortalité de l'Ohio de 1989 à 1991 pour les personnes de 18 ans et plus mortes de cause naturelle, l'étude estime les coefficients d'un modèle multivarié. Les effets de l'âge et de l'époque de l'année offrent des facteurs d'explication significatifs de la diffërence entre le jour du décès et l'anniversaire. Cependant, l'étude révèle aussi que la survenue du décès est plus probable dans la semaine qui suit l'anniversaire. Les résultats semblent donc corroborer l'hypothèse initiale de l'auteur.

Key Words: death-rise, death-dip, timing, mortality, seasonality, multivariate model, age effect 
A number of studies in the social sciences, and the medical and psychiatric fields have been concerned with the timing of death. These studies are concerned with the question as to whether individuals can control when their death occurs. In their early classic work on this subject, Phillips and Feldman (1973) found that there was a dip in deaths before ceremonial occasions (e.g., birthdays, religious holidays), and they attributed this decline to strength of social integrative forces upon different individuals.

The size of the death-dip before a ceremony appears to reflect the degree to which people are involved within that ceremony, and consequently the degree to which they are attached to that segment of the culture which is symbolized by that ceremony (Phillips and Feldman, 1973: 692).

Since famous people (e.g., presidents, industrialists, statesmen) are more attached to the social order, one would expect that they would experience a greater death-dip around their birthday (Phillips, 1972). Also, as one gets older and experiences symbolic-age birthdays (e.g., five- or ten-year intervals), one would expect a greater death-dip (Phillips and Smith, 1991).

Many scholarly studies have documented a death-dip for a number of individual, political, and religious occasions (Labovitz, 1974; Alderson, 1975; Barraclough and Shepherd, 1976; Phillips and Liu, 1980; Boor, 1981; Marriott and Fitzgerald, 1981; Barraclough and Hughes, 1987: 71-72; Phillips and King, 1988; Greiner and Pokorny, 1989-90; Phillips and Smith, 1990; Byers, Zeller and Byers, 1991). However, a number of other studies (Roger, 1977; Baltes, 1977-78; Kunz and Summers, 1979-80; Bradshaw, 1981; Geis, 1982; Harrison and Kroll, 1982; Kunz and Williams, 1982; Wasserman, 1983; Grigsby, 1985; Angermeyer, Kuhn and Osterwald, 1987; Harrison and Kroll, 1989-90; Walker and Walker, 1990) have found no effect for different samples with a range of control measures. There is no consensus in the literature regarding the validity of the findings, and theoretically there is a questioning of the assumption that one can in most cases control the timing of their death. ${ }^{1}$

This study will focus on one aspect of the timing of death-the birthday phenomenon, which concerns timing control in relation to an individual ceremonial event, unlike timing control in relation to religious and political events. The mathematical model is slightly different for the birthday timing issue than for the others, but in the future this type of model can be extended to these other studies.

Two basic problems with almost all the birthday studies is that they fail to clearly enumerate hypotheses that will be tested, and they also fail to develop 
a precise mathematical model that can test these hypotheses, controlling for seasonal effects and the influence of exogenous factors. Theoretical studies of this type are difficult, since one assumes individual motives for the behavior of deceased individuals that can never be fully verified, given the fact that the respondent is dead. Still, it is possible to specify alternative aggregate explanations for the findings, and determine how well the empirical data fits the various models. From a methodological perspective, it is necessary to develop a mathematical model that will allow for the simultaneous testing of the different aggregate explanations.

\section{Theoretical and Methodological Critique}

From an examination of the literature, it is possible to delineate four broad explanations for the deathday-birthday findings. First, one may conclude that the relationship is strictly random, and the supposed non-random findings may have resulted from the failure of investigators to control for seasonal effects, which will be discussed shortly. This explanation assumes that with proper seasonal controls the significant statistical findings will disappear.

A second hypothesis would argue that the relationship is caused by demographic and structural factors related to variations in mortality patterns with age. Demographically, as individuals age, their mortality rate increases significantly (Bogue, 1969: 548-622; Zopf, 1984: 180-212; Weeks, 1992: 157-191), and at the end of life, when individuals are 85 years of age and over, there is such a high decrease in their numbers after a birthday that it is more likely that individuals at this advanced age would die forward rather than backwards of their birthday. Prior to this older age, increased mortality rates during a year are either neutral, or favor death prior to the birthday.

The age distribution of deaths indicates that up to age seventy-five, the increasing death rate has more effect on the number of deaths (for birthdays and deathdays) than does the depleting population. At ages seventy-five to eighty four, when more than a quarter of the population dies, the rising death rate balances the declining population, resulting in a uniform distribution of death relative to the birthday. It is only at ages eighty-four and older, when less than a fifth of the population dies, that the declining population dominates the rising death rate (Wood, 1986-87: 322).

Thus, a portion of any assumed death-dip that may occur in a population is likely to be a function of the age composition of the population. The fact that studies of this behavior for famous people (Phillips, 1972; Phillips and Feldman, 1973; Angermeyer, Kuhn and Osterwald, 1987) yield different 
findings may be related to the age composition of the selected population.

A third hypothesis is the deathdip hypothesis, which argues that social integration causes individuals to delay their death in order to participate in the birthday ceremony (Phillips, 1972; Phillips and Feldman, 1973; Alderson, 1975; Barraclough and Shepherd, 1976; Phillips and Smith, 1991). This hypothesis assumes that individuals, by an act of will, can delay their death until they participate in a socially meaningful event that satisfies their social obligations. With regard to the elderly, the subjective assumptions of this model are questionable, since it has been found that the elderly tend to turn away from considerations of the future in order to avoid thoughts of their own death (Bascue and Lawrence, 1977-78), implying that the elderly tend not to orient their behavior around the ceremonial event of their birthday.

A fourth general model is the deathrise hypothesis, which assumes that birthdays increase social stress and anxiety among individuals (Engels, 1977; Kobruski, 1979; Grigsby, 1985; Greene et. al., 1987; The New York Times, 1993), and this increase makes it more likely that they will die on their birthday, or immediately after the birthday. Alcoholic consumption is seen as more socially appropriate at birthday celebrations (Wilks and Callan, 1988), and it is possible that this increased alcoholic consumption during this period may induce greater individual mortality. Rather than controlling mortality, this hypothesis argues that a birthday represents an exogenous risk $^{2}$ that increases stress and anxiety, and raises the mortality level around birthdays.

The previous studies on this subject also have a number of serious methodological flaws. First, almost all of them fail to develop a precise multivariate model which would allow for the control of seasonal forces and external variables. Most of the models are either descriptive (Alderson, 1975; Byers, Zeller and Byers, 1991), or else employ crude elaboration measures (Phillips and Feldman, 1973). A recent study by Grigsby (1985) does employ controls through an analysis of variance, but the work fails to control for seasonal effects.

Second, the previous studies tend to suffer because of their sample sizes. Many of the studies (Phillips, 1972; Barraclough and Hughes, 1987: 71-72) employ relatively small samples, and since the birthday effect is unlikely to be a large effect influencing most individuals in the sample, it is questionable that these studies will be able to detect a significant effect. The exception to this rule is the recent California study (Phillips, Van Voorhees and Ruth, 1992), which has two samples totaling 2,745,149 people. 
Third is the issue of what type of mortality to include in the analysis. Most studies either examine certain types of mortality (e.g., suicide (Barraclough and Hughes, 1987: 71-72, or motor vehicle fatalities (Kunz and Williams, 1983)), or else restrict their analysis to all individuals over a certain age. The California study (Phillips, Yan Voorhees and Ruth, 1992: 533-534) further restricted the analysis to exclude non-natural deaths and deaths that occurred during surgery. It is ' necessary to theoretically justify these restrictions in future studies.

Fourth, many of the previous studies employ too large time units of analysis, including months and quarters of the year (Phillips, 1972; Kunz and Summers, 1979-80; Kunz and Williams, 1983). Given the fact that the birthday-effect-is likely to be a-short-term result, it-is doubtful-that-such-longterm temporal studies will be able to accurately detect the effect. A recent study using a large data set for the state of Ohio (Byers, Zeller and Byers, 1991) used days as the unit of analysis, but the study failed to construct a multivariate model that would allow for the control of seasonal and exogenous effects.

Fifth, previous studies have failed to control for seasonal effects. A number of studies (Araki et. al., 1986; Bako et. al., 1988; Fossey and Shapiro, 1992) have shown that mortality follows a seasonal pattern, with the rate peaking in the cold months, probably because of the effect of the cold on the heart (Vuori, 1987). Similarly, fertility exhibits a seasonal pattern in most developed nations (Seiver, 1985; Trovato and Odynak, 1993), with the rate peaking in September in the United States. A recent sophisticated California birthday study (Phillips, Van Voorhees and Ruth, 1992) did introduce seasonal controls into the model. It may also be necessary to control for day of the week; since both fertility and mortality may vary among days of the week.

\section{Methodology}

In order to test the deathdip-deathrise hypothesis, mortality data from the state of Ohio between 1989 and 1991, which included 305,005 cases, will be examined.3 While all previous studies of this hypothesis have serious methodological flaws, one of the most sophisticated studies of this behavior with the largest sample, is the recent California study (Phillips, Van Voorhees and Ruth, 1992), which had two waves. The first wave from 1969 to 1977 had 1,389,334 respondents, while the second wave, between 1978 and 1990, had $1,438,815$ respondents. The two waves differed in that the second wave, which was the actual results examined, excluded individuals 
who died during surgery. The findings from this California study will be used as a reference for this study. Like the California research, this study will only consider individuals 18 years of age and over who died of natural causes. Since the information was not available, it was not possible to exclude individuals who died during surgery. ${ }^{4}$ This study will assume that the variation from the California study will not systematically bias the findings.

In order to develop a multivariate model to examine the hypothesis, it will be necessary to construct an algorithm, the dependent variable, that measures the degree to which an individual dies forward or backward of their birthday. The measure should be symmetric, so that the individual has an equal chance of dying forward or backward of their birthday. Let us number the days of the year from 1 (January 1st) to 365 (December 31st), excluding individuals who were born on February 29th. While this exclusion is necessary for symmetry reasons, it is also justified by the fact that individuals born on that date usually celebrate their birthday on some unknown date (Phillips, Van Voorhees and Ruth, 1992: 534). Using this numbering scheme, let us define:

Diff $=$ Difference of Deathday and Birthday $=$ Ddate-Bdate, where Ddate $=$ Numerical date of death

Bdate $=$ Numerical date of birth

Since the measure should be symmetrical, centered around 0 , let us transform Diff in the following manner:

$$
\begin{array}{lrrrl}
\text { If } & -182 & \text { Diff } & 182 & \text { then Diff }=\text { Diff } \\
\text { If } & 182 & \text { Diff } & 364 & \text { then Diff }=\text { Diff }-365 \\
\text { If } & -364 & \text { Diff } & -182 & \text { then Diff }=\text { Diff }+365
\end{array}
$$

By this transformation of Diff, a symmetrical measure centered around 0 , with a range between -182 and 182, has been created. By the law of large numbers, it may be assumed that for a large sample of individuals the mean value of Diff will be normally distributed. Figure 1 indicates the possible shape of the mean value of Diff and its range. A value centered around 0 would indicate a random distribution, while a curve centered significantly below zero would suggest a death rise, and a curve centered significantly above 0 would show a death dip. The transformed variable were treated as the dependent variable in the model. 
FIGURE 1. POSSIBLE DISTRIBUTION OF MEAN VALUE OF Di UNDER DIFFERENT CONDITIONS

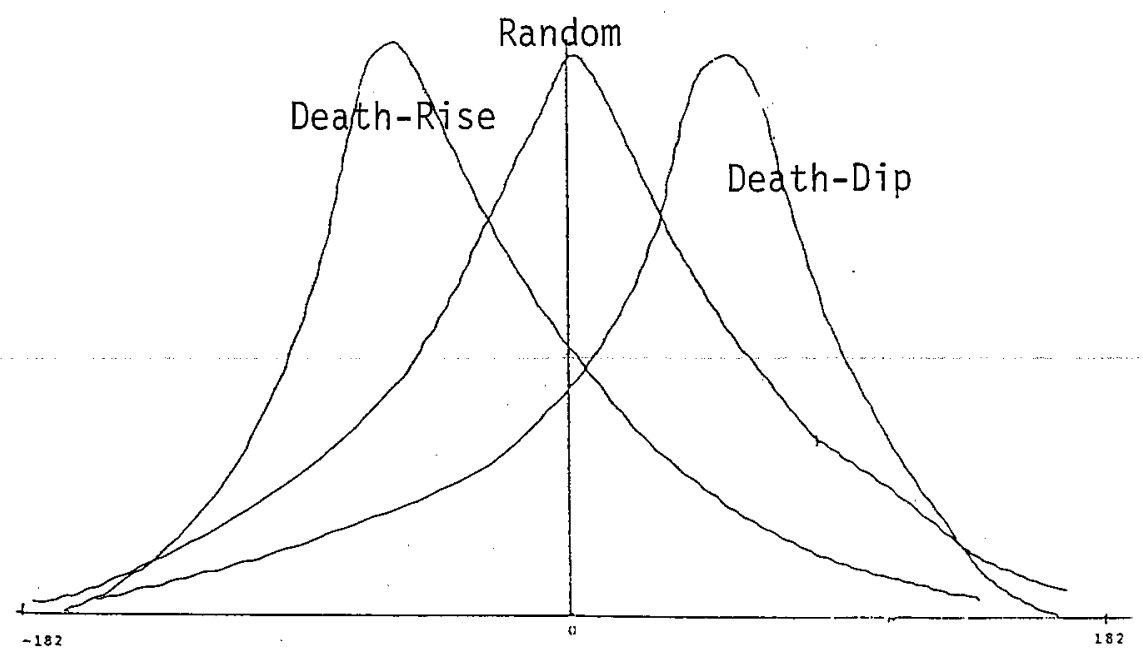

Di-Difference between Deathday and Birthday

In order to control for seasonal effects related to mortality and fertility, a number of seasonal variables were introduced into the model. Bollen (1983) provided a framework for this type of seasonal control when he examined temporal variations in suicide and motor vehicle fatalities in the United States between 1972 and 1976. Eleven dummy variables were created for month of death, and a similar procedure was followed for month of birth, December being arbitrarily eliminated in each case. Since number of deaths vary between the three years in Ohio, two dummy variables were created for year of death, 1991 being arbitrarily eliminated from the model.

It is possible that deaths and births may vary by day of the week. Using an SPSS conversion routine (SPSS, 1990: 23-25), it was possible to convert all days of death and birth to determine the day of the week (i.e., Sunday to Saturday) when they occurred. Table 1 indicates the distribution of deaths and births for the Ohio sample between 1989 and 1991. In general there is not strong daily variations for death and birth, but there is a tendency for more individuals to die on Monday, while slightly more births occur on weekends. Given this fact for both deaths and births, six dummy variables 
were created, Saturday being arbitrarily eliminated from the model in both cases.

TABLE 1. DISTRIBUTION OF DAYS OF THE WEEK FOR DEATHDAYS AND BIRTHDAYS FOR OHIO MORTALITY DATA

\begin{tabular}{lrrrrrrrr}
\multicolumn{8}{c}{ Day of the Week } \\
Sunday & Monday & Tuesday & $\begin{array}{c}\text { Wednesday } \\
\text { (Percentage) }\end{array}$ & & & \\
& & & & & & \\
14.1 & 14.5 & 14.4 & 14.1 & 14.2 & 14.4 & 14.5 & $(281,149)$ \\
14.5 & 14.5 & 14.2 & 14.1 & 14.3 & 14.2 & 14.4 & $(280,855)$ \\
\hline
\end{tabular}

Age and gender may interact with seasonal mortality patterns. For example, a study of seasonal suicide patterns in Finland (Nayha, 1982) found significant seasonal variations by gender, age and occupation. Given this fact, it was decided to interact age and gender with monthly and weekly mortality patterns.

It is necessary to control for a set of exogenous variables in order to be compatible with the California study and other similar studies (e.g., Byers, Zeller and Byers, 1991). In particular, age, gender, race, marital status and education were introduced into the model. Earlier studies (Wood, 1986-87) found that age significantly influenced the difference between deathday and birthday (Di), especially for individuals 84 years of age and older. This finding would suggest that a linear relationship would be inappropriate for examining the connection between age and Di. Rather, it was necessary to use a polynomial regression model (Neter, Wasserman and Kutner, 1990: $315-348$ ), which relates age and age 2 to $\mathrm{Di}$. The mean age for the Ohio mortality sample was $\mathbf{7 3 . 5 3}$ years, and it was necessary to transform age in the model to (age-73.53) in order to reduce the multicollinearity in the model (Neter, Wasserman and Kutner, 1990: 315-316).

Race was defined as a dummy variable, 0 being nonwhite, and 1 being white. Gender was also be defined as a dummy variable, 0 being female, and 1 being male. The level of formal education for the respondents was coded in the following manner: "1" was 8 years of schooling or less, "2" was 9 to 11 years of education, "3" was 12 years of formal education, "4" was 1 to 3 years of college, "5" was a college graduate, and "6" was 5 or more years of 
college. In order to determine whether a deathdip was present, a dummy variable was created, where an individual obtained a score of " 1 " if they had died a week before their birthday, and a score of " 0 " otherwise. In order to determine whether there was a deathrise, an individual was given a score of "1" if they had died on their birthday or a week forward of their birthday, and a score of " 0 " otherwise.

In order to estimate the 78 independent variables in the multivariate model, ordinary least square (OLS) estimates were employed. A number of statistical checks were required in order to assure that this estimation procedure can be employed. First, it was necessary to check for outliers by examining the standardized residuals. If the standardized residuals were greater than 3 to 4 units,-one-can -assume that outliers were-present -in the data. However, if these outliers were fewer than 1 to $2 \%$ of all the data points, they could be safely ignored. The Ohio data set had only 115 outliers, and in no case was the " $Z$ " residual greater than 2.0 .

Second, it was necessary to check for multicollinearity by examining the condition index (Belsley, Kuh and Welsch, 1980: 105; Gujarati, 1988: 301302 ). If the condition index was greater than 30 but less than 1000 , moderate multicollinearity existed, but if the index was over 1000 , severe multicollinearity was evident. An examination of the condition index for the 78 independent variables showed that none had a value greater than 30 , indicating the absence of multicollinearity in the data set.

Third, it was necessary to check for heteroscedasticity, or change in the variance of "Y" as "X" increases. The Park test (Gujarati, 1988: 329-330) was employed to test for heteroscedasticity in the Ohio data. The test treated the square of the residual term as the dependent variable, and the transformed log of all the independent variables as the new independent variables in the model. The test then examined the slope coefficients of the transformed independent variables, and if none were significant, heteroscedasticity was absent. None of the slope coefficients in the Ohio date were significant at the .05 level, indicating an absence of heteroscedasticity.

\section{Findings}

Table 2 shows the slope coefficients and the " $t$ " values for the variables in the model. The multiple " $R$ " value was .0413 , and an analysis of variance test yielded an " $\mathrm{F}$ " value of 5.568 , which was significant at the .01 level. While the multiple " $\mathrm{R}$ " value was low, it was high in relation to the size of 
the sample, which was over 250,000 .

None of the monthly seasonal effects for month of death were significant at the .05 level, and neither were day of the week in relation to death. For birth month, many of the monthly variables were significant, but none of the daily effects were significant. The two yearly effect measures also were not significant this level. None of the seasonal variables for mortality interacting with age were significant at the .05 level, and the only seasonal variable interacting with gender that was significant was that for deaths occurring on Friday. In general, the seasonal variables have little influence on explaining variation between day of death and day of birth.

The findings of the impact of age on $\mathrm{Di}$, were consistent with Wood's (198687) assertion that with advanced age the relationship becomes stronger. Both first- and second-order coefficients were significant in Table 2, but the second-order term had a stronger effect on Di than the first-order term, and both effects were positive. At age 84 and older, the high mortality rate of the remaining cohort caused a strong increase in mortality in the period after the birthday. The relationship between age and Di was weak and linear until age 84 , at which time the curve slopes strongly upward.

Table 2 implies that the relationship between gender, race, and educational level were not significant. The California study (Phillips, Van Voorhees and Ruth, 1992) established that women were more likely to die in the week following their birthday, but these findings do not support this result. However, this study shows that married individuals are more likely to die in the week following their birthday, an outcome consistent with an earlier Ohio study between 1979 and 1981 (Byers, Zeller, and Byers, 1991: 23), which also found a forward effect.

With regard to the fall and increase of deaths around the birthday, the study finds that in the week prior to the birthday there was a significant decrease in deaths and on the birthday, and in the week forward of the birthday there was a significant increase in deaths. The forward effect is slightly higher than the backward effect, as demonstrated by the value of the two " $t$ " statistics. 
Testing the Deathdip and Deathrise Hypothesis: Ohio Mortality Results, 1989-1991

TABLE 2. SLOPES AND T-VALUES RELATING SEASONAL VARIABLES, THE INTERACTION OF SEASONAL VARIABLES WITH AGE AND GENDER, AND OTHER NDEPENDENT VARIABLES TO DIFFERENCES IN DEATHDAY AND BIRTHDAY FOR INDIVIDUALS 18 YEARS AND OLDER WHO DIED OF NATURAL CAUSES IN OHIO BETWEEN 1989 AND 1991

\begin{tabular}{|c|c|c|c|}
\hline Variables & Slope & t-Value & \\
\hline Constant & 1.13 & 0.66 & \\
\hline \multicolumn{4}{|l|}{ Seasonal Variables } \\
\hline January Death & 6.66 & 1.20 & \\
\hline February Death & -6.81 & -1.20 & \\
\hline March Death & -6.35 & -1.13 & \\
\hline April Death & 3.89 & 0.69 & \\
\hline May Death & 3.54 & 0.63 & \\
\hline June Death & 1.94 & 0.34 & \\
\hline July Death & -1.10 & -0.19 & \\
\hline August Death & -2.57 & -0.45 & \\
\hline September Death & -0.79 & -0.14 & \\
\hline October Death & 0.03 & 0.01 & \\
\hline November Death & 7.03 & $1.24^{*}$ & \\
\hline January Birth & -2.84 & $-2.78^{*}$ & \\
\hline February Birth & -4.80 & $-4.64^{*}$ & \\
\hline March Birth & -6.91 & $-6.82 *$ & \\
\hline April Birth & -8.27 & $-7.99 *$ & \\
\hline May Birth & -8.66 & $-8.41^{*}$ & \\
\hline June Birth & -6.58 & $-6.34^{*}$ & \\
\hline July Birth & -3.16 & -3.09 & \\
\hline August Birth & -1.41 & -1.39 & \\
\hline September Birth & 0.69 & 0.67 & \\
\hline October Birth & 0.37 & 0.36 & \\
\hline November Birth & 0.30 & 0.29 & \\
\hline Sunday Death & 4.33 & 1.00 & \\
\hline Monday Death & 6.66 & 1.54 & \\
\hline Tuesday Death & -0.75 & -0.17 & \\
\hline Wednesday Death & 2.29 & 0.52 & \\
\hline Thursday Death & 1.50 & 0.34 & \\
\hline Friday Death & 1.32 & 0.30 & \\
\hline Sunday Birth & -0.24 & -0.03 & \\
\hline Monday Birth & 1.32 & 1.70 & \\
\hline Tuesday Birth & 0.59 & 0.76 & \\
\hline Wednesday Birth & 0.99 & 1.27 & \\
\hline Thursday Birth & 0.16 & 0.21 & \\
\hline Friday Birth & 0.09 & 0.12 & \\
\hline $1989^{\circ}$ & 0.06 & 0.12 & \\
\hline 1990 & -0.31 & -0.62 & \\
\hline
\end{tabular}

table cont'd next page 
table cont'd

\begin{tabular}{|c|c|c|}
\hline \multicolumn{3}{|l|}{ Seasonal Death Variables with Age } \\
\hline Age * January Death & -0.08 & -1.17 \\
\hline Age * February Death & 0.07 & 1.03 \\
\hline Age * March Death & 0.07 & 1.04 \\
\hline Age * April Death & -0.07 & -1.01 \\
\hline Age * May Death & -0.04 & -0.61 \\
\hline Age * June Death & -0.05 & -0.65 \\
\hline Age * July Death & 0.05 & 0.65 \\
\hline Age * August Death & 0.07 & 0.93 \\
\hline Age * September Death & -0.02 & -0.28 \\
\hline Age * October Death & -0.02 & -0.32 \\
\hline Age * November Death & -0.10 & -1.43 \\
\hline Age * Sunday Death & -0.07 & -1.20 \\
\hline Age * Monday Death & -0.08 & -1.52 \\
\hline Age * Tuesday Death & 0.03 & 0.55 \\
\hline Age * Wednesday Death & -0.02 & -0.36 \\
\hline Age * Thursday Death & -0.04 & -0.65 \\
\hline Age * Friday Death & 0.01 & 0.11 \\
\hline Seasonal Death Variables with Ger & & \\
\hline Gender * January Death & 1.02 & 0.52 \\
\hline Gender * February Death & 0.25 & 0.12 \\
\hline Gender * March Death & -0.76 & -0.38 \\
\hline Gender * April Death & -2.11 & -1.04 \\
\hline Gender * May Death & -1.84 & -0.90 \\
\hline Gender * June Death & 0.94 & 0.46 \\
\hline Gender * July Death & -0.82 & -0.40 \\
\hline Gender * August Death & 1.30 & 0.63 \\
\hline Gender * September Death & 3.37 & 1.63 \\
\hline Gender * October Death & -1.20 & -0.59 \\
\hline Gender * November Death & -1.18 & -0.59 \\
\hline Gender * Sunday Death & -0.34 & -0.21 \\
\hline Gender * Monday Death & -1.89 & -1.19 \\
\hline Gender * Tuesday Death & -2.39 & -1.51 \\
\hline Gender * Wednesday Death & -1.63 & -1.02 \\
\hline Gender * Thursday Death & 0.32 & $0.20^{*}$ \\
\hline Gender * Friday Death & -3.12 & -1.97 \\
\hline Other Independent Variables & & \\
\hline (Age-73.53)2 & 0.16 & $2.58^{*}$ \\
\hline (Age-73.53) & 0.01 & 3.85 \\
\hline Gender & 1.50 & $0.88^{*}$ \\
\hline Marital Status & 2.06 & 4.32 \\
\hline Race & -0.30 & -0.40 \\
\hline Educational Level & 0.14 & $0.82 *$ \\
\hline Died Week Prior to Birthday & -3.55 & $-2.32 *$ \\
\hline Died on Birth or 1 Week Forward & 3.65 & 2.56 \\
\hline Multip & & \\
\hline
\end{tabular}

\footnotetext{
* Significant at .05 level.
} 


\section{Discussion}

The scholarly literature on the birthday-deathday problem has been extensive, but no study has developed an algorithm and a multivariate model allowing for the control of seasonal effects, and also the control of seasonal effects with other variables. This study has developed a symmetric measure determining the difference between deathday and birthday, and has related this measure to seasonal effects, the interaction of seasonal effects with age and gender, as well as to other independent variables, using OLS estimates.

Replicating a recent California investigation (Phillips, Van Voorhees and Ruth, 1992) (it was not possible to eliminate surgery deaths), it was discovered that the previous work was incorrect indicating that gender was significantly linked with the difference (Di). However, many of the findings of this study are consistent with previous works on the subject. There is a curvilinear relationship between $\mathrm{Di}$ and age, with the relationship becoming stronger after age 84. Also, married individuals are more likely to die forward of their birthday.

The findings that are difficult to interpret are the significant fall in deaths prior to the birthday (a deathdip), and the rise in deaths on the birthday and the week after the birthday (a deathrise). The significant deathdip findings are consistent with the position that birthdays are related to social integration, and individuals delay their death until after this ceremonial event. On the other hand, the deathrise after the birthday is consistent with the position that birthdays increase social stress for individuals (e.g., further anxiety and drinking), which leads to an increase in their mortality level. In order to further test these two explanations, it will be necessary in future studies to deaggregate the causes of death (e.g., cancer deaths, lung disease, cardiovascular deaths), and apply the multivariate model to these different causes of death. One would hypothesize that certain types of mortality (e.g., cardiovascular deaths) are more related to social stress than other types of mortality.

In summary, the findings in this study are consistent with other studies that demonstrate that birthdays do influence individual mortality patterns. Also, it shows that all seasonal effects have a weak effect on explaining variations between deathdays and birthdays. Finally, the findings show that there is a weak, although significant, relationship between $\mathrm{Di}$ and other variables. Death patterns are altered around birthdays, but the alteration is slight. 
Notes

1 In volitional mortality, such as many non-natural deaths (e.g., suicides, homicides, accidents), this control may have existed in some cases, but in most cases it was likely not present.

2. In a recent article on risk management, Morgan (1993) argues that the more educated, who are more rational, engage in a process of risk minimization. If the deathrise hypothesis is correct, rational individuals might wish to avoid ceremonies connected with their birthday.

3. The authors would like to thank Dr. Edward Stockwell of the Population and Society Research Center at Bowling Green State University for kindly supplying the Ohio mortality data for 1989-1991.

4. This study has information on the Ohio mortality tape on individuals who died as in-patients in hospitals, but it is not possible to conclude that all these individuals died as the result of surgery.

\section{References}

Alderson, M. 1975. Relationship between month of birth and month of death in the elderly. British Journal of Preventive and Social Medicine 29: 151-156.

Angermeyer, M.C., L. Kuhn and P. Osterwald. 1987. Birthday and date of death. Journal of Epidemiology and Community Health 41: 121-126.

Araki, S. et. al. 1986. Seasonal variation in suicide rates by cause and sex. Journal of Biosocial Science 18: 471-478.

Bako, G. et. al. 1988. Seasonality of mortality from various diseases in Canada 1979-83. Canadian Journal of Public Health 79: 388-389.

Baltes, M.M. 1977-78. On the relationship between significant yearly events and time of death: Random or systematic distribution? Omega 8: 165-172.

Barraclough, B.M. and J. Hughes. 1987. Suicide. Clinical and Epidemiological Studies. London, England: Croom-Helm.

Barraclough, B.M. and D.M. Sheperd. 1976. Birthday blues: The association of birthday with selfinflicted death in the elderly. Acta Psychiatria Scandinivica 54: 146-149.

Bascue, L.O. and R.E. Lawrence. 1977-78. A study of subjective time and death anxiety in the elderly. Omega 8: 81-90.

Belsley, D., E. Kuh and R.E. Welsch. 1980. Regression Diagnostics: Identifying Influential. Data and Sources of Collinearity. New York, NY: John Wiley and Sons.

Bogue, D.J. 1969. Principles of Demography. New York, NY: John Wiley and Sons.

Bollen, K.A. 1983. Temporal variations in mortality: A comparison of U.S. suicides and motor vehicle fatalities, 1972-1976. Demography 20: 45-59.

Boor, M. 1981. Effect of United States presidential elections on suicide and other causes of death. American Sociological Review 46: 616-618. 
Bradshaw, C.W., Jr. 1981. A re-examination of Phillips' death-dip hypothesis. The Journal of General Psychology 105: 265-267.

Byers, B., R.A. Zeller and P.Y. Byers. 1991, Birthdate and mortality: An evaluation of the death-dip death-rise phenomenon. Sociological Focus 24: 13-28.

Cohen, J. and P. Cohen. 1983. Applied Multiple Regression/Correlation Analysis for the Behavioral Sciences. Second Edition. Hillsdale, New Jersey: Lawrence Erlbaum Associates.

Engel, G. 1977. Emotional stress and sudden death. Psychology Today 11 (November): 114-118.

Fossey, E.and C.M. Shapiro. Seasonality in psychiatry-A review. Canadian Journal of Psychiatry 37: 299-308.

Geis, G. 1982. Birthdays and time of death: A footnote. Omega 13: $91-93$.

Greene; D. et. al: 1987. Birthdays: Journal of Psychosocial Nursing 25:9=13.

Greiner, T. and AD. Pokomy. 1989-90. Can death be postponed: The death-dip phenomenon in psychiatric patients. Omega 20: 117-126.

Grigsby, J.S. 1985. Special occasions, stress and mortality: Do people tend to die during their birth month? Social Biology 32: 102-114.

Gujarati, D. 1988. Basic Econometrics. Second Edition. New York, NY: McGraw-Hill Book Company.

Harrison, A.A and N.E.A. Kroll. 1982. Birth dates and death dates: A closer look. Omega 13: 117125.

1989-90. Birth dates and death dates: An examination of two baseline procedures and age and time of death. Omega 20: 127-137.

Kobrinski, E. 1979. Birthdays and stressful life events in the elderly. PAS Reporter. Special Issue. 46 (August): 56-61.

Kunz, P.R. and J. Summers. 1979-80. A time to die: A study of the relationship of birthdays and time of death. Omega 10:281-289.

Kunz, P.R. and C. Williams. 1983. Automobile accidents and birthdays: An attempted extension of the "death dip" hypothesis. Social Biology 30: 106-108.

Labovitz, S. 1974. Control over death: The Canadian case. Omega 10: 281-289.

Marriott, C. and J.M. Fitzgerald. 1981. Nixon's resignation and death rates: Individual/system interaction in America. Omega 12: 107-115.

Morgan, M.C. 1993. Risk analysis and management. Scientific American 269 (7): 32-41.

Nayha, S. 1982. Autumn incidence of suicides re-examined: Data from Finland by sex, age and occupation. British Journal of Psychiatry 141: 512-517.

Neter, J., W. Wasserman and M.H. Kutner. 1990. Applied Linear Statistical Models. Regression, Analysis of Variance, and Experimental Designs. Homewood, Illinois: Irwin. 
The New York Times. 1992. Chances of heart attack are greatest on birthday. The New York Times. (March 19, p.A8.)

Phillips, D.P. 1972. Deathday and birthday: An unexpected connection. Pp. 52-65. In J.M. Tanur et. al. (eds.) Statistics: A Guide to the Unknown. San Francisco, CA: Holden-Day Inc.

Phillips, D.P. and K.A. Feldman. 1973. A dip in deaths before ceremonial occasions: Some new relationships between social integration and mortality. American Sociological Review 38: 678-696.

Phillips, D.P. and J. Lui. 1980. The frequency of suicides and major public holidays: Some surprising findings. Suicide and Life-Threatening Behavior 10: 41-50.

Phillips, D.P. and E. W. King. 1988. Death takes a holiday: Mortality surrounding major special occasions. Lancet (September 24): 728-732.

Phillips, D.P. and D.S. Smith. 1990. Postponement of death until symbolically meaningful occasions. Journal of the American Medical Association 263: 1947-1951,

1991. Suicide at symbolic ages. Death on stocktaking occasions. In A. Leenaars (ed.) Life span Perspectives of Suicide. New York, NY: Plenium.

Phillips, D.P., C.A Van Voorhees, and T.E. Ruth. 1992. The birthday: Lifeline or deadline? Psychosomatic Medicine 54: 532-542.

Roger, J.H. 1977. An explanation for the observed increase in mortality after a birthday in people over 75 years old. British Journal of Preventive and Social Medicine 31: 62-64.

Seiver, D.A 1085. Trend and variation in the seasonality of U.S. fertility, 1947-1976. Demography 22: 89-100.

SPSS. 1990. SPSS Reference Guide. Chicago, Ill: SPSS Inc.

Trovato, F. and D. Odynak. 1993. The seasonality of births in Canada and the provinces, 18811989: Theory and analysis. Canadian Studies in Population 20: 1-41.

Vuori, I. 1987. The heart and the cold. Annals of Clinical Research 19: 156-162.

Walker, L. and L.D. Walker. 1990. Anniversary reaction: Important events and timing of death in a group of Roman Catholic priests. Omega 21: 69-74.

Wasserman, I.M. 1983. Political business cycles, presidential elections, and suicide and mortality patterns. American Sociological Review 48: 711-720.

Weeks, J.R. 1992. Population: An Introduction to Concepts and Issues. Fifth Edition. Belmont, CA: Wadsworth Publishing Company.

Wilks, J. and V.J. Callan. 1988. Explanations about appropriate drinking contents: Comparison of parents, adolescents and best friends. British Joumal of Addiction 83: 1055-1062.

Wood, J.B. 1986-87. The birthday-deathday effect: Fact or artifact Omega 17: 321-326.

Zopf, P.E., Jr. 1984. Population: An Introduction to Social Demography. Palo Alto, CA: Mayfield Publishing Company. 